\title{
Field behaviour of hybrid bolt at LaRonde Mine
}

\author{
P. Turcotte Agnico-Eagle Mines Ltd, Canada
}

\begin{abstract}
Agnico-Eagle's flagship LaRonde Mine is exploiting a world-class Au-Ag-Cu-Zn-Pb massive sulphide lenses complex. It is located in the Abitibi Region of north-western Quebec, approximately $650 \mathrm{~km}$ northwest of Montreal. With 4.8 million ounces of gold in proven and probable reserves, LaRonde has one of the largest gold reserves of any mine operating in Canada. These reserves extend from surface down to 3,110 metres and remain open at depth. The 2,250 metre Penna Shaft, which is believed to be the deepest single-lift shaft in the Western Hemisphere, is used to hoist LaRonde's ore production of approximately 7,200 tonnes per day. Current mining operations are taking place at over 2,400 metres below surface.

Due to the large vertical dimension of the orebody, mining operations intersect a wide variety of environments. As the stress to strength ratio of the rock rises, the behaviour of the rock mass changes drastically, from hard and brittle, to weak and squeezing. As a result, rock mechanics and ground control practices have evolved considerably as mining activities progressed deeper and the limits of conventional support systems were reached. Previous publications reported on preliminary results of the 'hybrid bolt'. This new type of reinforcement was developed jointly by ground control personnel and employees in an effort to improve ground support performance in squeezing ground. After three years of intensive use in any and all possible ground conditions encountered at the mine (over 44,000 installed bolts), it is felt that sufficient experience has been acquired to provide an update on the advantages and shortcomings of this new bolt.
\end{abstract}

\section{$1 \quad$ Introduction}

Agnico-Eagle Mines Ltd is a gold producer with six producing mines in three different countries. LaRonde Mine is located in the town of Pressiac in north-western Quebec. LaRonde, the company's flagship mine, achieves a steady production of 7,200 tonnes per day using the 2,250 metre Penna Shaft. Production comes from three different lenses whereby zone 20 constitutes the main mineralisation. The mine life has been estimated to 2024 with 4.8 million ounces of proven and probable gold reserves. The orebody also hosts zinc, copper, lead and silver by-products. Over $14 \mathrm{~km}$ of lateral development has been planned in 2010. A mine extension was approved in 2006 to extract the orebody between 2,450 and 3,110 m. A winze has been sunk to extract the ore from this new horizon and is estimated to be in production in 2013. A longitudinal view of LaRonde Mine can be seen in Figure 1 below.

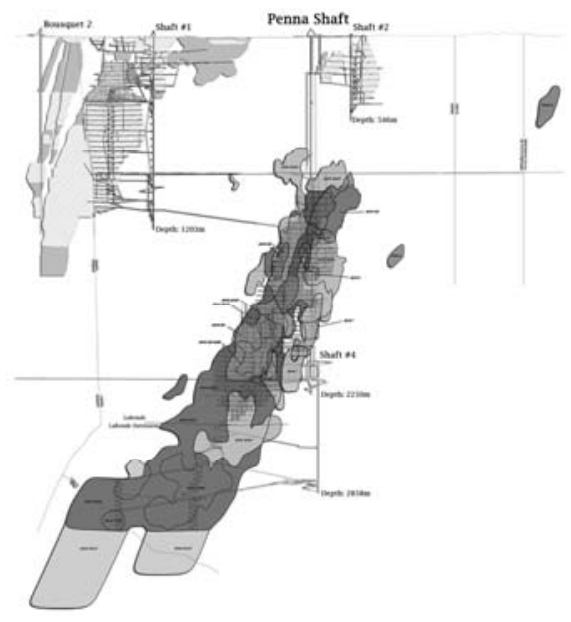

Figure 1 Longitudinal view of LaRonde Division 
Mitigated ground support performances have been observed in squeezing ground. These observations have been the initial point for development of a new support system by the ground control personnel and in collaboration with underground employees. Called hybrid bolt, the bolt were installed in different conditions at LaRonde and this paper documents experiences acquired after three years of intense use.

\subsection{Geology and field stresses}

The in situ stresses are estimated by the equations provided in Table 1. As an indication, calculated values at the elevation of 215 Level are given.

Table 1 Stress gradients at LaRonde Mine

\begin{tabular}{lll}
\hline Component & Equation & Level 215 \\
\hline$\sigma_{1}$ & $8.62+0.04 \mathrm{z}$ & $95 \mathrm{MPa}$ \\
$\sigma_{2}$ & $5.39+0.0262 \mathrm{z}$ & $62 \mathrm{MPa}$ \\
$\sigma_{3}$ & $0.0281 \mathrm{z}$ & $60 \mathrm{MPa}$ \\
\hline
\end{tabular}

The intact strength of the rocks found at LaRonde is deceptively good for the majority of the geological domains (Table 2).

Table 2 LaRonde mechanical properties of intact rock

\begin{tabular}{lll}
\hline Rock Type & UCS (MPa) & E (GPa) \\
\hline Basalt & 100 & 50 \\
Intermediate tuff & 100 & 48 \\
Massive sulphide & 140 & 53 \\
Semi-massive sulphide & 85 & 47 \\
Mineralised felsic tuff & 140 & 58 \\
\hline
\end{tabular}

Typically, permanent infrastructures are developed in the basalt host rock. However, the majority of haulage drifts and drawpoints are developed in felsic tuff which is characterised by a tightly (centimetre to decimetre) spaced foliation dipping approximately 75 to 80 degrees towards the south and parallel at the orebody (Mercier-Langevin and Turcotte, 2007). This unit is also characterised by localised sericite alteration zones, which typically present a tighter spacing of the foliation planes and overall lower rock mass properties (lower intact rock and joint resistance).

It follows that in the deeper levels of the mine, where induced stresses can be very high and rock mass properties can be vary greatly, ground control is one of the key challenges at the mine.

\section{Rock mass behaviour}

As a result of the large dimension of the operation (mining activity between 1,020 to 2,450 m), geology and stress conditions, a wide range of rock mass behaviour is observed. Ground conditions have been observed to be quite variable. Within a single level, both aseismic failure of soft and squeezing rock and violent failure of hard and brittle rock can be observed (Figure 2), with everything in between. 




Figure 1 Typical level layout below 215 Level showing observed ground control challenges

\subsection{Seismicity}

Some areas of the mine can exhibit significant levels of seismicity (magnitudes up to Richter 3.0). The great majority of larger events are confined to within a few seconds of final stope blasts (Mercier-Langevin and Hudyma, 2007), inside proactively closed-off areas. Although not a common occurrence, some of these events can result in rockbursts.

One of the first ground control strategies employed at LaRonde to manage seismicity was to introduce the modified cone bolt (MCB) (in conjunction with heavy gauge mesh straps) in order to increase the energy absorption capacity of existing support. However, quality control issues at installation were a problem. Furthermore, field evidence suggested that the energy dissipation capacity of the MCBs could not be guaranteed in squeezing foliated ground (Simser et al., 2006). As a result, the bolt was removed from the support standards.

\subsection{Squeezing ground}

Due to the fact that they are developed semi-parallel to the foliation, haulage drifts walls are subject to the most difficult conditions at LaRonde (Mercier-Langevin and Turcotte, 2007). In particular, the walls exhibit a buckling failure which, in certain areas of the mine can result in over a metre of closure (Figure 3).

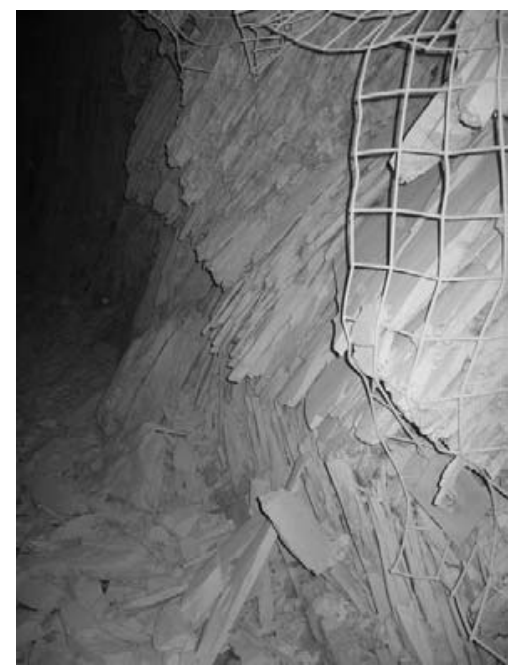

Figure 3 Typical foliation and buckling caused by sericite alteration - 233 Level 
Due to the nature of the failed material in the walls (foliated hard rock), massive shearing forces are induced on the foliation planes as the buckling movement takes place. As a result of this movement, most yielding support types tend to get kinked, which prevents them from yielding (Figure 4). As failure continues to progress, static load accumulates on the plate until either the bolt head or the plate fails. In worst cases, the bolts are "guillotined" inside the rock mass and fail without visible sign. In both situations, the screen is no longer held in place and the fractured rock becomes unconfined risking material spillage and drift wall degradation.

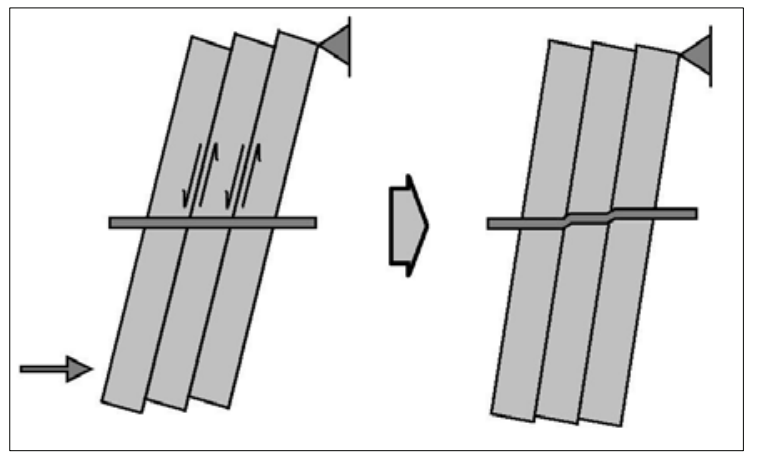

Figure 4 Common foliation planes movement observed at LaRonde (after Mercier-Langevin and Turcotte, 2007)

In the upper levels of the mine, where stresses are relatively low and the rock mass relatively competent, this mechanism is still manageable with standard friction bolts. As such, the mine's support standard in the walls, consisting in $2.0 \mathrm{~m}$ friction set bolt on a $0.9 \times 0.9 \mathrm{~m}$ pattern performs for the drift life. However, in deeper areas of the mine, particularly on the alteration-prone west flank, this pattern has proved to be suitable only for short term use.

When convergence reaches a point where wall stability is compromised or if equipment clearance is insufficient, the common practice is to purge the walls with a $7.3 \mathrm{~m}$ scooptram to remove the excess material. This operation is very sensitive and is always performed under close supervision from ground control personnel. As it is difficult to control the amount of broken material that falls off, the final size of the drift often largely exceeds its original dimensions. It is then necessary to install secondary back support, such as cable bolts, in order to stabilise the greater spans created by scaling of the side walls. This rehabilitation process is costly and time-consuming. Therefore, it is used only in last resort.

\section{$3 \quad$ Hybrid bolt development}

\subsection{First experience}

In 2006, an alimak ventilation raise was excavated in the lower mine. The original development procedure was to drive the raise using only friction set bolts on a $1.2 \times 1.2 \mathrm{~m}$ square pattern. Upon completion of the excavation phase, stiffer support composed of resin grouted rebar bolts were to be installed with screen to ensure the long term stability of the raise. Poor ground conditions were reported during excavation, with multiple scaling episodes needed to complete the raise. For the second phase, ground conditions were so poor that it proved impossible to tension the resin rebars. Almost all of the resin was lost in fractured ground, so that not enough was left to even coat the bolt.

The solution used to circumvent that problem was to employ a 'sleeve' system in order to prevent the release of resin into the surrounding fractured ground. A friction set bolt slightly longer than the rebar was be used as the 'sleeve'. The assembly was called a 'hybrid bolt'. Following a few adjustments to the process, bolting resumed in the raise without any more problems. This raise has been stable for over three years.

The successful commissioning of the ventilation raise prompted the ground control personnel to take a closer look at the properties of the hybrid bolt in order to assess its usefulness as a standard ground support element in squeezing ground, which, by that time, had become a real concern. In the deeper levels of the mine, head failure of friction set bolts took place very early in the development process and purging operations were 
performed almost routinely. The mine had been actively researching other avenues to control extreme wall deformations. Numerous support systems were put to the test, with disappointing results in most cases. The ideal ground support would be able to handle the following conditions:

- Capability to be installed in highly fractured ground

- High bolt head strength

- Yield at constant high tonnage

- High resistance to shear (acting on foliation planes).

The promising early results of the hybrid bolt made it the next best alternative.

\subsection{Properties of the hybrid bolt and field testing}

A pull test campaign was executed in the mine on 224 Level in a haulage drive. The results of these tests are displayed in Figure 5.

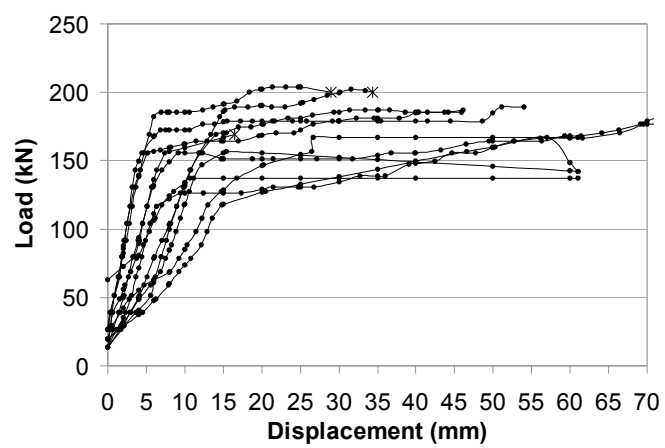

Figure 5 Results of the first hybrid bolt pull tests (after Mercier-Langevin and Turcotte, 2007)

Typically, during deformation, the load increases drastically in the first 5 to $10 \mathrm{~mm}$ movement, after which the friction bolt begins to slide at a steady rate, forces varying from 140 to $180 \mathrm{kN}$. The three bolts that failed did so in the weaker threaded section of the rebar which are used to anchor the testing rig to the bolt. One of these failed at the shear pin. The hybrid bolt displayed excellent results:

- The bolt could easily be installed in highly fractured ground

- The high capacity of its head prevented early failure

- It yielded at a constant high tonnage (approximately 15 tonnes).

Because its resistance to shear could only be evaluated in the field with long term installations, a test area was chosen to compare the hybrid bolt with standard support. The 218-35E footwall haulage drift was selected because of its very high deformation potential. The drift was also in close proximity to the orebody and the 215 sill pillar. After only three months, and significant wall closure, the hybrid bolt displayed a unique ability to control wall deformation. It significantly outperformed any other type of support that had been tried over the years. Because of these results, ground control personnel made the decision to implement the bolt in the ground support standard for squeezing ground.

\subsection{Installation}

Experience in very difficult ground has taught that the most efficient way to install the hybrid bolt at LaRonde is to follow the steps illustrated in Figure 6:

1. A hole is drilled $(\varnothing 37 \mathrm{~mm})$ and a $2.0 \mathrm{~m}$ friction bolt $(\varnothing 39 \mathrm{~mm})$ is installed with the resin already inside it in order to prevent broken fragments of rock from entering the bolt and hampering the next steps. The friction bolt is installed with a plate to hold the screen. 
2. A $1.9 \mathrm{~m}$ rebar $(\varnothing 22 \mathrm{~mm})$ is installed inside the friction bolt and spun following the specific requirements of the resin used. The rebar has its own plate to prevent early failure of the friction bolt head.

3. The rebar nut is tightened to push the plate against the head and plate of the friction bolt.



Figure 6 Procedure used to install the hybrid bolt at LaRonde (after Mercier-Langevin and Turcotte, 2007)

Note: This installation results in an internal hole diameter of $\varnothing 30 \mathrm{~mm}$ (for the rebar), making the ideal rebar diameter to use $\varnothing 22 \mathrm{~mm}$. This guarantees an optimum resin annulus of 3.5 to $4 \mathrm{~mm}$ (Hagan, 2003). Since the first resin cartridge is generally lost in the void present at the end of the hole, it is good practice to first install one 'slow' setting resin cartridge at the toe of the hole and the 'fast' resin cartridges second. The use of fast resin is not necessary for the bolt to work as designed and the grouting medium could be composed of slow resin exclusively, or even of cement grout. However, the reader should keep in mind that the presented methodology was optimised for elements already used at LaRonde, and various adjustments to this process should be possible in different operations.

\section{$4 \quad$ Field behaviour}

In April 2007, the hybrid bolt was first introduced as part of LaRonde's ground support standards. Since then, over 17,000 hybrid bolts have been installed in any and all ground conditions at the mine. As a result, a considerable amount of experience has been gained, some of which are discussed.

\subsection{Behaviour in squeezing ground}

Initial use of the hybrid bolt was in squeezing ground conditions. As part of the standard, the bolts would be installed following a $1.2 \times 1.2 \mathrm{~m}$ pattern (at the screen overlap), in conjunction with friction set bolts (which were installed in the centre of the screen). Figure 7 shows the typical behaviour exhibited by a haulage drift (footwall side of foliation) that was experiencing squeezing ground conditions with this type of support. Three metres from the drift face nearly all the friction bolts had failed. However, all hybrid bolts had remained intact. 


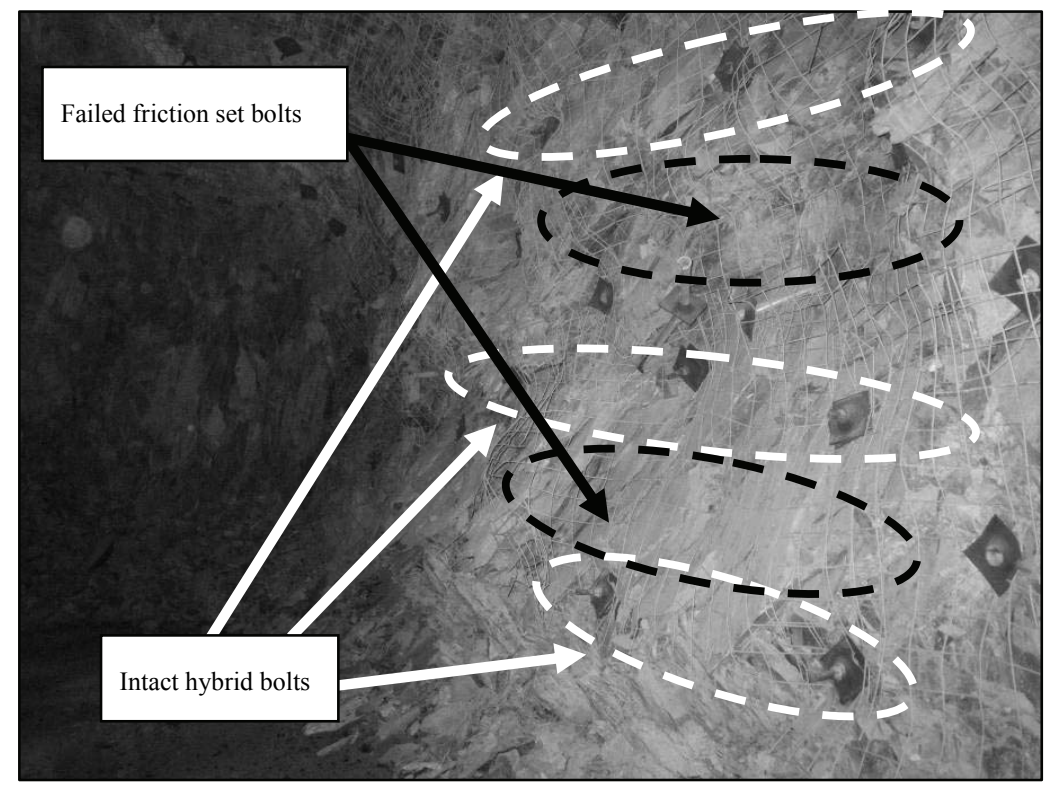

Figure 7 Hybrid bolts installed in squeezing ground - 227 Level

Although wall convergence was not eliminated, it was evident that the higher confinement provided by the hybrid bolts affected the failure mechanism in some manner. Squeezing in drifts supported only with friction bolts resulted in lifting of the footwall layers near the floor of the drift and toppling of the hanging wall layers near the shoulder. However, with hybrid bolts installed, the increased confinement resulted in a more even displacement profile of the wall (moved in the drift as a single plane, Figure 8). As a result, it would be possible to employ haulage drives for their planned life without major rehabilitation.

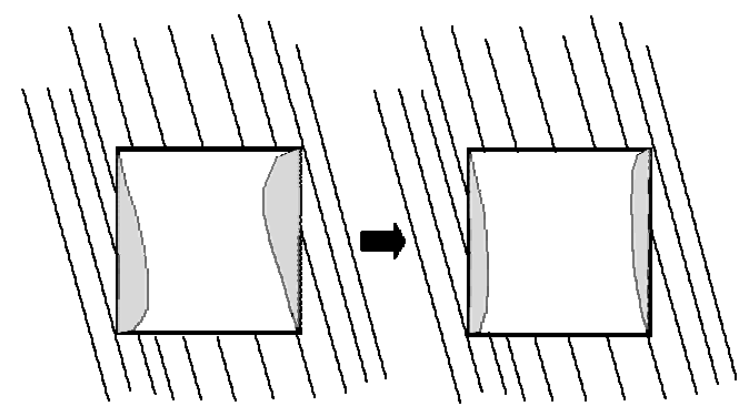

Figure 8 Modification of the drift shape after introduction of hybrid bolt (schematic)

Although the bolts performed well, some bolts were observed to sink into the wall, and some others had reached failure. This implied that some of the bolts became 'locked' by foliation planes, although later in the failure process, and for a limited number of bolts. Figure 9 shows a conceptual bolt reaction curves with the rock mass. If the bolt is installed too soon in the failure process, even its high capacity is not enough for the bolt and the rock mass to reach equilibrium. As a result, it was decided that the hybrid bolts would be installed as a secondary support, $12 \mathrm{~m}$ behind advancing faces (with heavy gauge mesh straps), at the same time final bolting of the lower walls was performed. This delay allowed the ground to deform to some extent without loading the primary support (friction sets) to failure. 


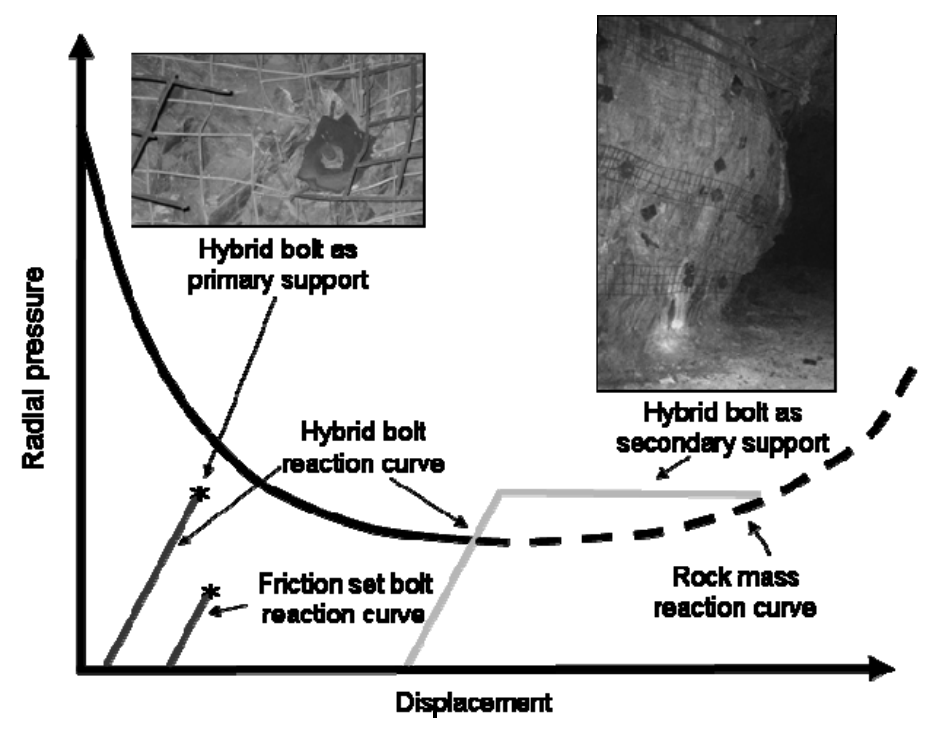

Figure 9 Conceptual reaction curve for the wall (adapted Hoek and Brown, 1980)

This new strategy had major impact on the operation. Figure 10 shows the cumulative distance of purging below the 215 Level since 2006. The graph demonstrates a significant reduction in the number of purging operations needed after the hybrid bolt was introduced in the bolting standards. A nearly $50 \%$ reduction in purging distance was also observed. The reduction of time-consuming purging jobs also had the side effect of increasing equipment availability for priority headings.

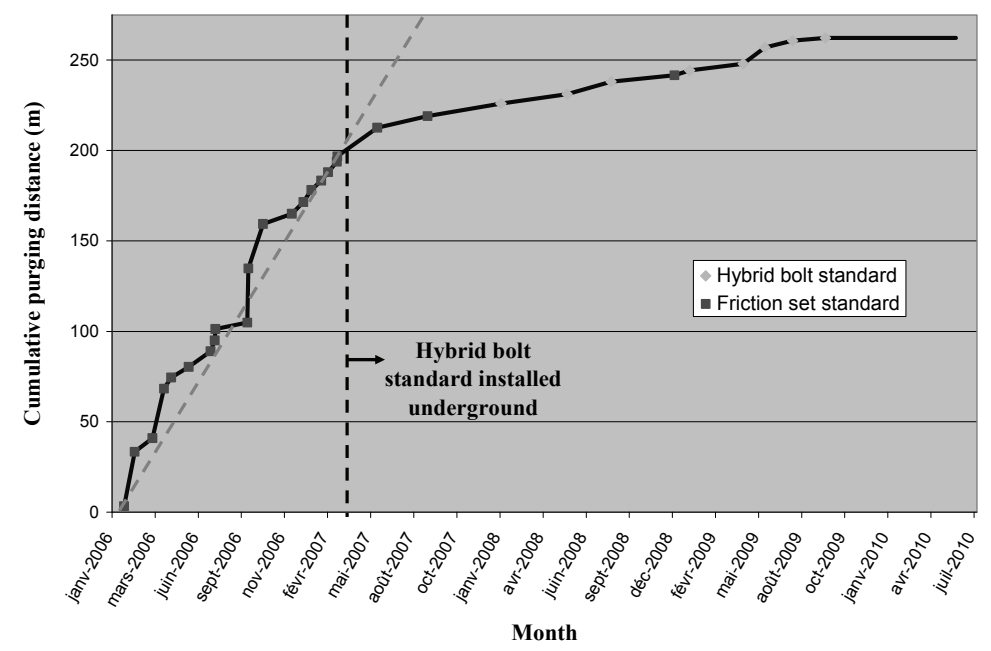

Figure 10 Cumulative distance purged under the 215 Level

\subsection{Behaviour in dynamic ground conditions}

In January 2007, a seismic event occurred at the 224 Level, exactly where the first pull tests were performed on the hybrid bolt. The event registered as a 1.9 Nuttli magnitude and resulted in projection of material from the bottom part of the north wall. The ground support installed in the drift wall included wire mesh and friction bolts installed on a $1.2 \times 0.6 \mathrm{~m}$ staggered pattern. Closer inspection of the damage suggested that the row of hybrid bolts had somewhat limited the propagation of damage to the upper part of the wall (Figure 11). Over the next few months, additional anecdotal evidence also suggested that the hybrid bolt could potentially be used as part of a dynamic support system. Since no replacement for the MCB had been found at that time, it was decided that hybrid bolts would be employed with horizontal 0 gauge mine straps in areas of high seismic risk. 


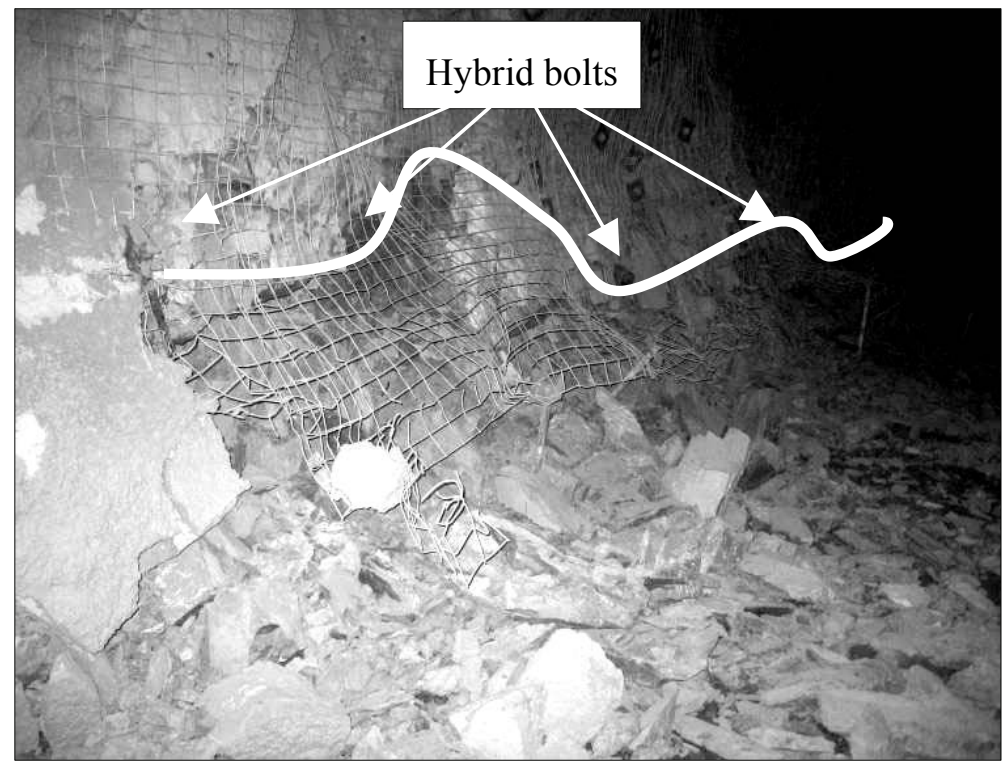

Figure 11 Support failure 'limited' by hybrid bolts - 224 Level

Two case studies provide an interesting comparison of similar events occurring in similar conditions, but with different outcomes (Figure 12). Both events recorded approximately the same magnitude (MR 2.5 Nuttli) and are believed to be caused by a similar fault slip mechanism. However, damage was quite different for the two sites. The events displaced approximately $60 \mathrm{t}$ on 182 Level compared with $3 \mathrm{t}$ on 224 Level. In the first case, friction sets and screen were installed whereas the other drift used friction sets and screen combined with hybrid bolts and 0 gauge mesh straps. One mesh strap failed but it was attributed to poor installation and corrosive water.

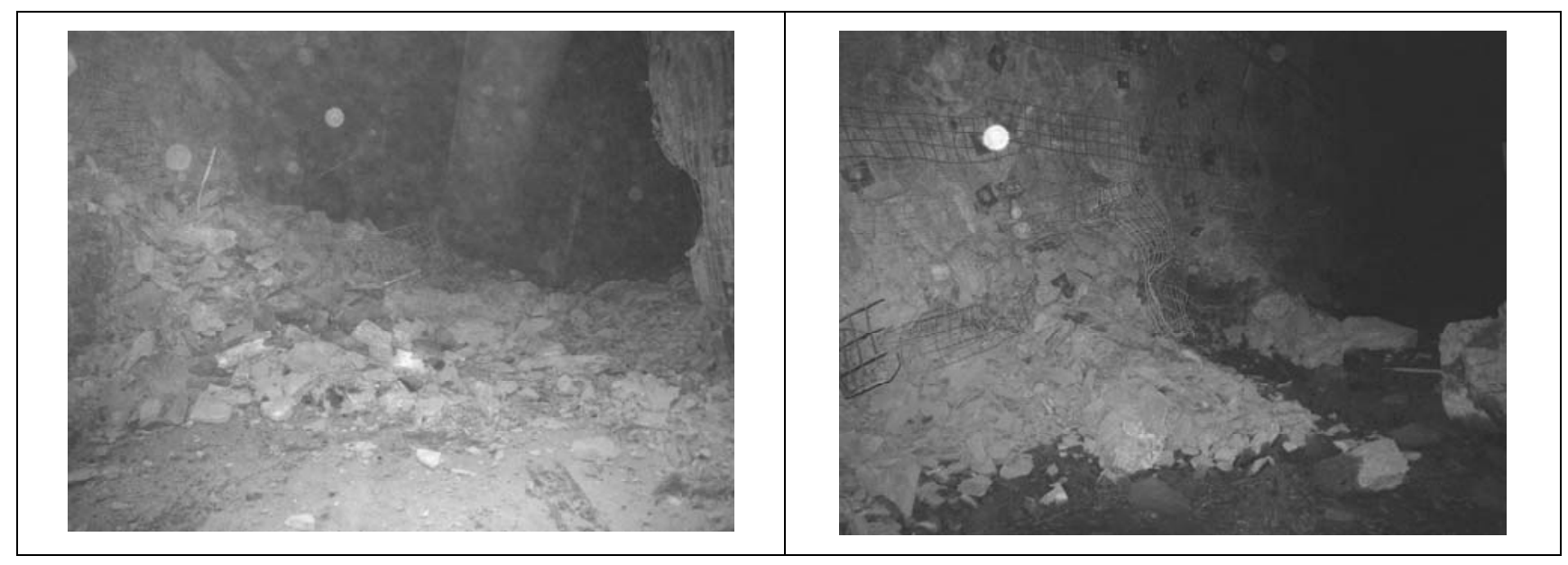

a) 182 Level : Standard ground support

b) 224 Level : Hybrid bolts with mine straps

Figure 12 Two locations hit by similar magnitude events but different support systems

Even though any single example does not constitute irrefutable proof of the bolt's capacity to dissipate seismic energy, a sufficient number of situations hinting at this have occurred over the last three years to prompt a closer examination of historic trends in seismicity at the mine. The following graph (Figure 13) tracks the cumulative displaced material (line/diamond) versus time since 2005. Cumulative number of large events (ML > 0) is shown as the dotted line. As can be seen, even though the frequency of occurrence of large events increased, the slope of the cumulative displaced material curve flattens sharply within a few months of the introduction of the hybrid bolt as dynamic support at the mine. Changes in the mining practices were implemented in the same time period (end of 2008), so that it is difficult to differentiate its 
effects from those of the hybrid bolt. However, it is doubtful that these changes were solely responsible for this shift. Combined with three years of accumulated anecdotal evidence in the field such as the one presented earlier, this data makes a convincing argument that the hybrid bolt might have significantly better energy dissipating capabilities than conventional friction bolts, when used in conjunction with heavy gauge mesh straps.

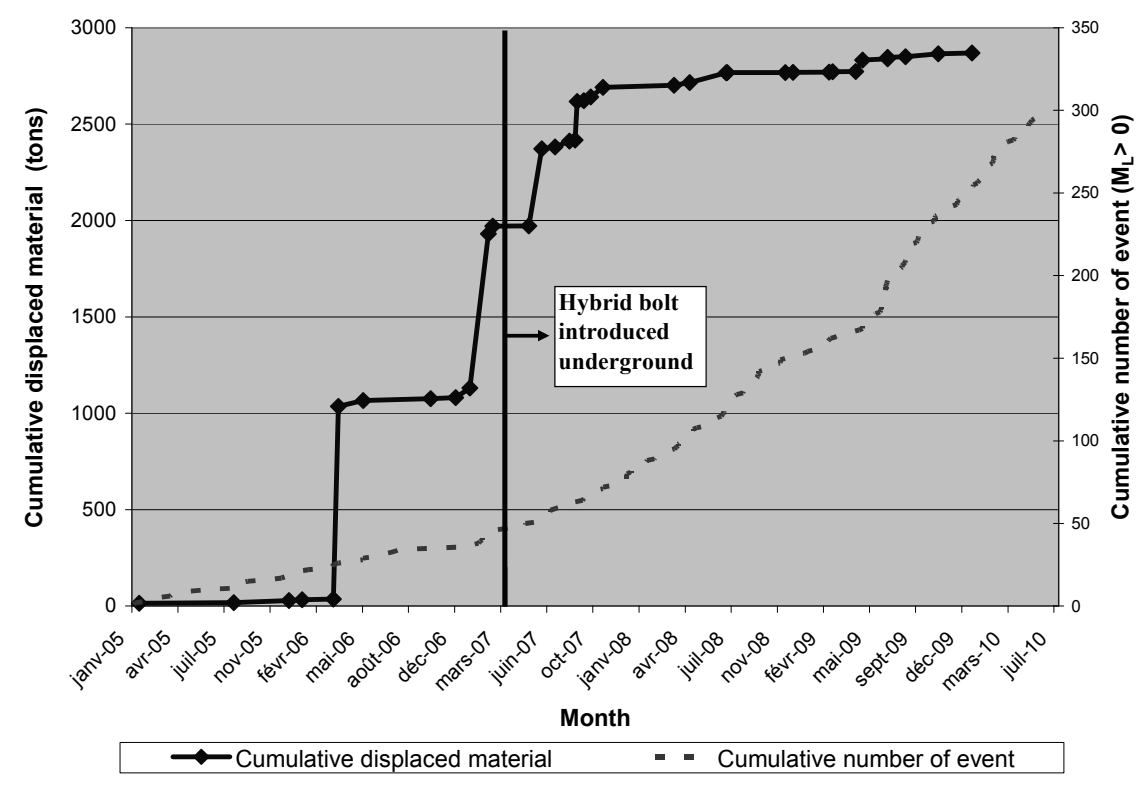

Figure 13 Quantity of displaced material versus cumulative number of seismic events at LaRonde since 2005

\subsection{Other mines}

The recently opened Lapa mine, also owned by Agnico-Eagle Mines, has to deal with squeezing ground issues in their ore drives (running parallel to the rock fabric). In light of the promising performance of the bolt at LaRonde, the mine decided to give it a try. A year after its introduction, the mine reports that it has improved overall wall stability in squeezing ground and that the number of 'purging' was favourably influenced as well.

\section{Conclusion}

Field evidence suggests that the introduction of the hybrid bolt at LaRonde has significantly improved stability in haulage drives in squeezing ground conditions. Whether excavations are subjected to seismicity or large scale ground deformations, the hybrid bolt has proven to be a vital element of LaRonde's ground control strategy. After three years of continued use in some of the worst ground conditions encountered at the mine, it has proven to be a versatile and dependable tool for ground control personnel. Reports of its performance in other mines suggest that the successful use of the hybrid bolt is not restricted to LaRonde's ground conditions but can be exported to other mines faced with similar ground control challenges.

\section{References}

Hagan, P.C. (2003) The effect of resin annulus on anchorage performance of fully encapsulated rockbolts, in Proceedings 10th International Congress on Rock Mechanics, September 8-11 2003, South African Institute of Mining and Metallurgy, Johannesburg, South Africa.

Hoek, E. and Brown, E.T (1980) Underground Excavations in Rock, The Institute of Mining and Metallurgy, London, p. 527.

Mercier-Langevin, F. and Hudyma, M. (2007) The development and implementation of a comprehensive seismic risk management plan at Agnico-Eagle's LaRonde Mine, in Proceedings 4th International Seminar on Deep and High Stress Mining, Y. Potvin (ed), Australian Centre for Geomechanics, Perth, Australia, pp. 221-232. 
Mercier-Langevin, F. and Turcotte, P. (2007) Evolution of ground support practices at Agnico-Eagle's LaRonde Division - Innovative solutions to high stress yielding ground, in Proceedings 1st Canada-US Rock Mechanics Symposium, Vancouver, Canada.

Simser, B., Andrieux, P., Mercier-Langevin, F., Parrott, T. and Turcotte, P. (2006) Field behaviour and Failure Modes of Modified Conebolts at the Craig, LaRonde and Brunswick Mines in Canada, Proceedings 3rd International Seminar on Deep and High Stress Mining, Quebec, Canada. 
